\title{
Nuevos procesos de expansión metropolitana: incremento acelerado de suelo urbano en el Área Metropolitana de Rosario (1990-2010)
}

Cecilia Galimberti. Universidad de la Costa (CUc), Barranquilla, Colombia.

RESUMEN | Desde las últimas décadas del siglo xx, gran parte de los territorios a nivel global atraviesan nuevas dinámicas metropolitanas y acelerados procesos de transformación. El presente artículo interpreta las características que registran las expansiones urbanas latinoamericanas, sus causas e impactos socioterritoriales, tomando como caso de estudio el Área Metropolitana de Rosario (AMR), Argentina. A través de una metodología cuali-cuantitativa y mediante un abordaje multiescalar, se analiza el proceso de creación de suelo urbano del AmR desde la década de 1930 hasta la actualidad, identificando las nuevas urbanizaciones, las dinámicas poblacionales del área, los actores intervinientes y los instrumentos de planeamiento urbano-territorial. Se identifica así que las localidades que presentan un mayor incremento de suelo urbano son aquellas cercanas a la ciudad cabecera y carentes de planes urbanos, registrando lógicas y problemáticas particulares con relación a las existentes en la ciudad tradicional.

PALABRAS CLAVE $\mid$ metropolización, expansión urbana, fragmentación urbana.

ABSTRACT | During the last decades of the twentieth century, various global territories have been experiencing new metropolitan dynamics and accelerated processes of transformation. This article interprets the characteristics of Latin American urban expansions, their causes and socio-territorial impacts, using the Metropolitan Area of Rosario (AMR), Argentina as a case study. Through a qualitative-quantitative methodology and through a multiscale approach, we analyze the development of urban land from the 1930s to the present, identifying new urbanizations, population dynamics, intervening actors and urban-territorial planning instruments. It is thus identified that the localities that present a greater increase of urban land are those close to the capital city and lacking urban plans, registering logics and problems in relation to those existing in the traditional city.

KEYWORDs | metropolization, urban sprawl, urban fragmentation. 


\section{Introducción}

Especialmente desde las últimas décadas del siglo xx, las demandas del mercado, los cambios productivos, los desarrollos tecnológicos, entre otros factores, plantean a nivel mundial nuevas formas de organización y relaciones espaciales. Frente a estos procesos, asociados mayormente a las dinámicas del capitalismo y de la globalización, se generan transformaciones que tienen su correlato territorial. En este contexto, se producen cambios en las lógicas de las regiones que conducen hacia una nueva metropolización. Los ámbitos metropolitanos están sujetos a diversas presiones y dinámicas externas, mientras los condicionantes locales asumen y transforman, a su vez, los vínculos existentes en cada territorio. Se registran, así, metamorfosis de la interfaz urbano-rural, dado que estos ámbitos geográficos se transforman aceleradamente. Una de tales transformaciones es un incremento de las movilidades y la emergencia de morfologías espaciales que modifican sustancialmente el uso tradicional del espacio metropolitano y el consumo de suelo. En este sentido, se registra un notable aumento de las actividades urbanas por sobre las propias de ámbitos rurales. Las geografías de la urbanización adquieren nuevas morfologías que atraviesan y perforan la antigua división entre lo urbano y lo rural (Brenner, 2016). Si bien esta tendencia se denota a nivel global, en los ámbitos latinoamericanos se profundizan estas transformaciones frente a una estructura históricamente desigual en los ámbitos social, económico y territorial (Ciccolella, 2014). Los procesos de expansión urbana en las regiones metropolitanas de América Latina registran espacios duales, caracterizados tanto por la presencia de barrios privados y asentamientos irregulares, como por la sumatoria de numerosas decisiones individuales yuxtapuestas.

El proceso de suburbanización residencial, si bien ocurre a nivel global, en Argentina se constituye como una de las dimensiones más emblemáticas y radicales del proceso de privatización que atraviesa el país, especialmente desde la década de 1990. Las nuevas modalidades de urbanización surgidas desde entonces se vinculan directamente con el aumento de las desigualdades sociales y la crisis del Estado (Svampa, 2001). Los pobladores de los territorios concernidos por el proceso señalado provienen mayormente de dos éxodos: por un lado, movimientos migratorios procedentes de otras regiones, atraídos por las posibilidades que brinda la ciudad cabecera del área en materia de trabajo y servicios, y cuyos integrantes, al no poder acceder al mercado de suelo en la misma, se asientan en poblados aledańos. Por otro lado, también se produce la migración de familias pertenecientes a la ciudad central que, en búsqueda de un modo de vida de mayor contacto con la naturaleza o también por no poder acceder a una vivienda propia con tal característica en la urbe principal, deciden instalarse en las localidades cercanas a ella.

En este contexto, se toma como caso de estudio el Área Metropolitana de Rosario (AMR), una de las tres áreas metropolitanas más pobladas de la Argentina, luego de Buenos Aires y Córdoba. El AMr constituye un ejemplo relevante para analizar y comprender los múltiples procesos complejos que tienen lugar en las metrópolis contemporáneas. En los últimos treinta años, las localidades que la conforman han 
experimentado acelerados cambios en los usos de suelo, dado que cientos de hectáreas rurales han sido transformadas a suelo urbano, mayormente para residencia.

El objetivo general del presente trabajo es profundizar en el entendimiento de las dinámicas contemporáneas de expansión urbana en las áreas metropolitanas de América Latina. Asimismo, se plantea comprender las relaciones entre las políticas y normativas de urbanización, el rol del Estado, los desarrolladores inmobiliarios y los ciudadanos, en aquella acelerada transformación de suelo rural a urbano que ha generado un modelo de expansión generalizada y de baja densidad. Se parte de la hipótesis según la cual la carencia de planes urbanos y políticas de ordenamiento urbano-territorial en localidades próximas a la ciudad cabecera del AMR, donde predomina el suelo rural, posibilita que se desarrollen nuevas urbanizaciones promovidas por agentes privados, con tendencia a la dispersión y notables carencias de servicios e infraestructura.

Este estudio se realiza mayormente desde una metodología cuali-cuantitativa, ya que si bien se trata de captar los elementos cualitativos clave de la realidad estudiada -sus lógicas y reglas implícitas y explícitas-, tales análisis se contrastan con datos cuantitativos provenientes de dos fuentes principales: los Censos Nacionales de Población, Hogares y Viviendas (Instituto Nacional de Estadística y Censos, INDEC) correspondientes a los años 1991, 2001 y 2010; y las bases georreferenciadas del Servicio de Catastro e Información Territorial de la provincia de Santa Fe (sciT), información incorporada mediante Sistemas de Información Geográfica (sIG) que nos posibilitan identificar las trasformaciones de suelo, de rural a urbano, durante los siglos xx y xxI. Asimismo, se realiza un estudio comparativo de imágenes satelitales históricas y actuales de los distintos municipios y comunas pertenecientes al AMR disponibles en Google Earth, y el relevamiento y análisis crítico de las ordenanzas de usos del suelo y planes urbanos de las comunas y municipios pertenecientes al AMR. La información ha sido confirmada por trabajo de campo, a través del cual se realizaron registros fotográficos y cartográficos de los cambios de usos del suelo.

El artículo se estructura en cuatro partes. En la primera, se expone el estado de situación de los procesos de expansión urbana en las metrópolis contemporáneas a nivel global, pero haciendo foco especialmente en las características de las dinámicas urbano-territoriales de las áreas metropolitanas latinoamericanas. En el segundo apartado se presenta el caso de estudio y se realiza una breve síntesis de los cambios espaciales y tendencias a la creación de suelo urbano en dicha área durante el siglo xx, para así comprender las lógicas históricas de urbanización de este territorio. En la tercera parte se desarrolla el análisis de las transformaciones que han ocurrido en el AMr desde las últimas décadas del siglo xx, haciendo énfasis en el incremento poblacional y del suelo urbano que ha tenido lugar en el período 1990-2010 en las comunas y ciudades aledañas a Rosario. A partir de un abordaje multiescalar, se expone sintéticamente la expansión urbana de toda el AMr en dicho arco temporal, luego se realiza un foco en el cuadrante oeste metropolitano y, finalmente, se interpretan las transformaciones espaciales registradas en la jurisdicción correspondiente a la comuna de Ibarlucea. En la cuarta parte, a modo de reflexiones finales, se esboza una serie de conclusiones que constituyen un aporte al conocimiento tanto de las dinámicas de expansión urbana generalizada de los ámbitos metropolitanos 
de América Latina, como de los procesos en curso del AMr, a fin de contribuir al desarrollo de instrumentos y políticas públicas que operen desde una perspectiva multiescalar y multiactoral.

\section{Procesos de expansión urbana en las áreas metropolitanas contemporáneas}

Las áreas metropolitanas, especialmente desde fines del siglo $\mathrm{xx}$, se encuentran sujetas a un acelerado proceso de cambio que, a pesar de las especificidades de cada contexto local, en términos generales se caracteriza por una notable expansión en el territorio, incrementándose la urbanización sobre las áreas rurales. Las realidades metropolitanas contemporáneas abordan una situación de gran complejidad que presenta fenómenos diversos, como las migraciones masivas, la exclusión territorial, la segregación y marginación social y otras situaciones directamente asociadas a las nuevas tendencias del proceso de urbanización global (Precedo Ledo, 2004).

En diversas partes del mundo se registran cambios de las lógicas de las formas urbanas en relación con su velocidad, magnitud y tendencia a la dispersión, la fragmentación y la baja densidad. Tales características se manifiestan mayormente en las denominadas áreas periurbanas, suburbanas o paisajes intermedios (Sieverts, 1997). Estos espacios geográficos, localizados entre ciudades, tradicionalmente de usos rurales, en las últimas décadas presentan una nueva configuración territorial, tanto en sus morfologías como en las actividades que se desarrollan en ellos, que distan de las categorías clásicas de campo y ciudad.

Se registran profundas transformaciones en la interfaz urbano-rural, identificándose un paisaje sin reglas aparentes, ilegible en la definición de sus partes y de sus interrelaciones. Este nuevo tipo de expansión urbana se distingue por un alto nivel de fragmentación, donde el suelo agrícola tiende a convertirse en espacios intersticiales. Estamos, así, ante la presencia de una red de cientos de kilómetros caracterizados por una semiurbanización desordenada, un nuevo asentamiento invasivo que no es ni campo ni ciudad (Bedini \& Bronzini, 2016).

La expansión metropolitana se caracteriza por presentar un modelo de dispersión urbana con patrones de baja densidad, vinculados a diversos cambios culturales y económicos en cuanto al acceso a la vivienda propia y a los modos de habitar anhelados por parte de la sociedad. Este tipo de crecimiento urbano está acompańado por una discontinuidad creciente y una gran fragmentación de las áreas suburbanas. Se generan, así, nuevas urbanizaciones aisladas, muchas veces cerradas, que se extienden en las afueras de los supuestos límites de la ciudad, de manera que la creciente polarización social conduce a una mayor fragmentación espacial, afectando tanto las áreas residenciales como las actividades comerciales, industriales, recreativas e, inclusive, rurales. Estos modelos tienden a generar, a su vez, un enorme incremento de la movilidad (García-Palomares, 2009).

Según la revisión bibliográfica de estudios de casos europeos, asiáticos y norteamericanos (Colsaet, Laurans, \& Levre, 2018), los principales factores determinantes en la expansión del suelo urbano son, en primer lugar, las políticas públicas, el rol del Estado y la regulación de los usos del suelo (planeamiento débil o inexistente); el aumento en la movilidad pluridireccional debido a la accesibilidad a 
vías de transporte, con la tendencia creciente al uso del automóvil individual; el incremento poblacional y migraciones; factores culturales y sociales, dado que se registra una aspiración a acceder a tipologías habitacionales unifamiliares aisladas o exentas, mayormente en los suburbios y vinculadas a un mayor consumo del suelo; factores económicos, vinculados a la especulación inmobiliaria y a la renta del suelo (rural-urbano); y las características geográficas y topográficas que condicionan que determinados sectores se vean sujetos a una creciente transformación.

De este modo, frente a la ausencia o debilidad de políticas de planeamiento urbano-territoriales integrales a nivel regional en las áreas metropolitanas, la expansión urbana es el resultado de la suma de miles de decisiones individuales, donde el Estado se comporta como facilitador. Se trata de una tendencia que acarrea múltiples consecuencias e impactos socioambientales, como, por ejemplo, la pérdida de espacios abiertos y la fragmentación de las áreas rurales, aumentos en las distancias de viaje, un mayor consumo de energía y de emisiones de gases de efecto invernadero como consecuencia de la proliferación de la movilidad motorizada (Dieleman $\&$ Wegener, 2004). Sin embargo, como fundamenta Bruegmann (2006), además de estos efectos negativos, también es relevante identificar las dinámicas y los beneficios por los cuales muchos habitantes han elegido residir en estos espacios intersticiales, como la posibilidad del acceso a la tierra para la construcción de vivienda propia en sectores más verdes, asociados a la naturaleza, y la promesa de una mayor seguridad con relación a determinadas áreas de los centros históricos.

Si bien los procesos de expansión urbana generalizada señalados se reconocen en la mayoría de las áreas metropolitanas de todo el planeta, en el contexto de América Latina presentan especificidades propias. Siguiendo a Van Noorloos y Steel (2016), en las ciudades latinoamericanas se profundiza el enfoque neoliberal del desarrollo urbano, que tiene como resultado un aumento de la mercantilización de la tierra. La conversión del suelo (de uso rural a urbano) resulta un producto comercializable intensificado por el auge inmobiliario dominado por desarrolladores e inversores tanto extranjeros como de las elites nacionales. Estas nuevas dinámicas de metropolización vinculadas a la urbanización expandida en Latinoamérica comenzaron a manifestarse en la década de 1980, profundizándose en las primeras décadas del siglo Xxi. Se registran así diversas metamorfosis urbanas que muestran un doble movimiento de dispersión y de concentración de las inversiones inmobiliarias, mayormente lideradas por políticas de desregulación, privatización y mercantilización, que producen una compresión espacio-temporal y permiten crear un espacio global de acumulación, con las morfologías urbano-territoriales resultantes (Hidalgo, Arenas, \& Santana, 2016).

En este contexto, se han profundizado diversos procesos privados de apropiación del espacio en nuevas áreas de expansión, generando un gran impacto en la configuración urbana de gran parte de las regiones de América Latina. Como explica De Mattos (2015), en el marco de la gobernanza neoliberal, junto al orden general impuesto por las dinámicas del mercado, tanto las familias como las empresas adquieren una mayor autonomía para seleccionar los espacios de localización, generando con ello un territorio metropolitano sujeto a profundas metamorfosis urbanas, entre los cuales se identifican nuevos patrones de autoorganización. Por 
ejemplo, respecto al hábitat se reconocen dos situaciones diferentes. Por un lado, está aquella vinculada a sectores altos y medios que, motivados por el interés de una vivienda unifamiliar con jardín propio, contribuye a la expansión urbana en las periferias de las ciudades de América Latina, muchas veces en el formato de de urbanizaciones cerradas. Y por otra parte, los sectores poblacionales de menores ingresos, frente a las dinámicas del mercado, tienden a ser relegados a las áreas de la periferia, con menores dotaciones de servicios e infraestructuras $y$, consecuentemente, menor valor del precio de la tierra.

Vinculados a los procesos seńalados se registran diversos impactos, entre los cuales se identifican nuevos patrones de inclusión/exclusión social, cambios en el acceso de los pobladores a servicios y recursos, consumo extensivo de suelo-muchas veces alejado de las ciudades existentes-, aumento de la demanda de infraestructuras de movilidad, vulnerabilidad ambiental y pérdida de ecosistemas (Heinrichs, Nuissl, \& Rodríguez Seeger, 2009). Como explica Pablo Ciccolella (2014), más allá de las particularidades de cada metrópolis, desde la década de 1990 se ha impuesto un modelo de gestión política y económica que otorga gran libertad de acción al ámbito privado como ordenador territorial, redefiniendo la relación entre lo público y lo privado. Se posibilita, así, un avance del capital como operador clave de las transformaciones urbano-territoriales, conformando tanto nuevas morfologías espaciales como cambios en las dinámicas sociales.

\section{Presentación del caso de estudio: desarrollo histórico de los procesos de expansión urbana en el AMR}

El Área Metropolitana de Rosario se encuentra en la provincia de Santa Fe, a orillas del río Paraná, a 300 km aproximadamente de la Capital Federal de la República Argentina. En el presente trabajo tomamos como delimitación del área lo establecido por el Ente de Coordinación Metropolitana de Rosario (ЕСОм), que considera que el AMR actualmente está integrada por Rosario y veintisiete comunas y municipios (figura 1).

Según datos censales de 2010, el AMr tiene una población total de 1.371.285 habitantes, de los cuales el 69\% pertenece a Rosario. Asimismo, esta localidad resulta la única con predominancia de suelo urbano. Sin embargo, a pesar del desbalance existente entre la ciudad cabecera y el resto de las localidades, en las últimas décadas se ha dado un acelerado cambio en las dinámicas poblacionales y en el uso del suelo de los distintos municipios y comunas que conforman el área.

El ámbito territorial estudiado comenzó a transformarse aceleradamente durante la segunda mitad del siglo xIx, a partir de la infraestructuración ferroportuaria y el desarrollo agrícola. La mayoría de los poblados que forman parte del AMR surgieron y crecieron en torno a las estaciones ferroviarias, las cuales, a su vez, han sido estructuradoras de los centros urbanos proveedores del puerto rosarino. Estos poblados constituyeron el área productora adyacente a lo que iba conformándose como la ciudad-puerto de Rosario, paralelamente a políticas de colonización agrícola. Rosario se convirtió así en puerta de entrada para la inmigración masiva y la salida de la producción cerealera, base de las exportaciones de la región. 


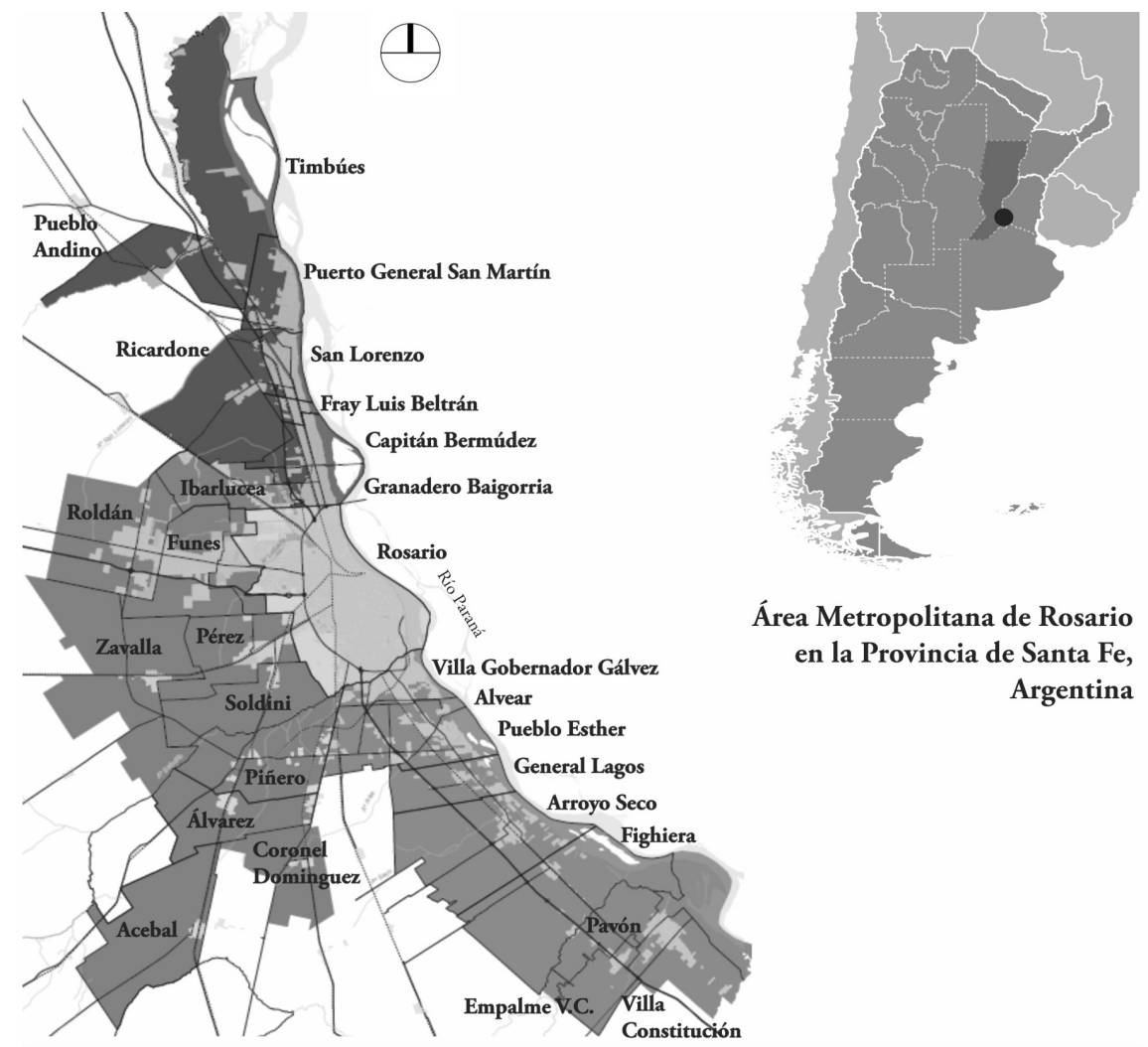

\begin{tabular}{|l|c|l|c|}
\hline \multicolumn{4}{|c|}{ ÁREA METROPOLITANA DE ROSARIO } \\
\hline LOCALIDAD & POBLACIÓN & \multicolumn{1}{c|}{ LOCALIDAD } & POBLACIóN \\
\hline Acebal & 5.377 & Pińero & 1.816 \\
\hline Álvarez & 6.175 & Pueblo Andino & 2.226 \\
\hline Alvear & 4.451 & Pueblo Esther & 7.195 \\
\hline Arroyo Seco & 21.710 & P.G. San martín & 13.409 \\
\hline Capitán Bermúdez & 29.425 & Ricardone & 2.703 \\
\hline Coronel Domínguez & 1.091 & Roldán & 14.299 \\
\hline Fighiera & 5.028 & Rosario & 948.312 \\
\hline Fray Luis Beltrán & 15.389 & San Lorenzo & 46.239 \\
\hline Funes & 23.520 & Soldini & 3.212 \\
\hline General Lagos & 4.112 & Timbúes & 4.294 \\
\hline Granadero Baigorria & 37.333 & Villa Constitución & 47.903 \\
\hline Ibarlucea & 4.402 & V.C Empalme & 6.410 \\
\hline Pavón & 1.880 & Villa Gobernador Gálvez & 80.769 \\
\hline Pérez & 27.439 & Zavalla & 5.166 \\
\hline Total población AMR & & & 1.371 .285 \\
\hline
\end{tabular}

FIGURA I | Localización y cantidad de población de las localidades del Área Metropolitana de Rosario, Santa Fe, Argentina

FUENTE: ELABORACIÓN PROPIA A PARTIR DE DATOS DEL CENSO 20 IO (INDEC) 
Entre las décadas de 1920 y 1930, frente a sucesos internacionales como la Primera Guerra Mundial y la crisis de 1929-1932, se desencadenó en Argentina un acelerado crecimiento de la industria nacional. En este contexto, diversas fábricas e industrias se instalaron en localidades cercanas a Rosario, generando nuevas transformaciones espaciales al atraer habitantes de otras regiones que se instalaron cerca de las industrias, en nuevas urbanizaciones. Esto sucedió, por ejemplo, con la instalación del Frigorífico Swift en la actual Villa Gobernador Gálvez, dado que entre 1924 y 1928 sus trabajadores se asentaron en las cercanías de la fábrica, conformando un núcleo urbano llamado Pueblo Nuevo. Otro ejemplo representativo es el de Celulosa Argentina, que se emplazó en 1929 a orillas del Paraná en la localidad de Capitán Bermúdez cumpliendo un rol fundamental en la urbanización aledańa a la fábrica, dado que promovió la compra de tierras destinadas a la construcción de barrios para sus trabajadores con vivienda incluida, incorporando a ellos equipamientos culturales y recreativos, como el Club Celulosa.

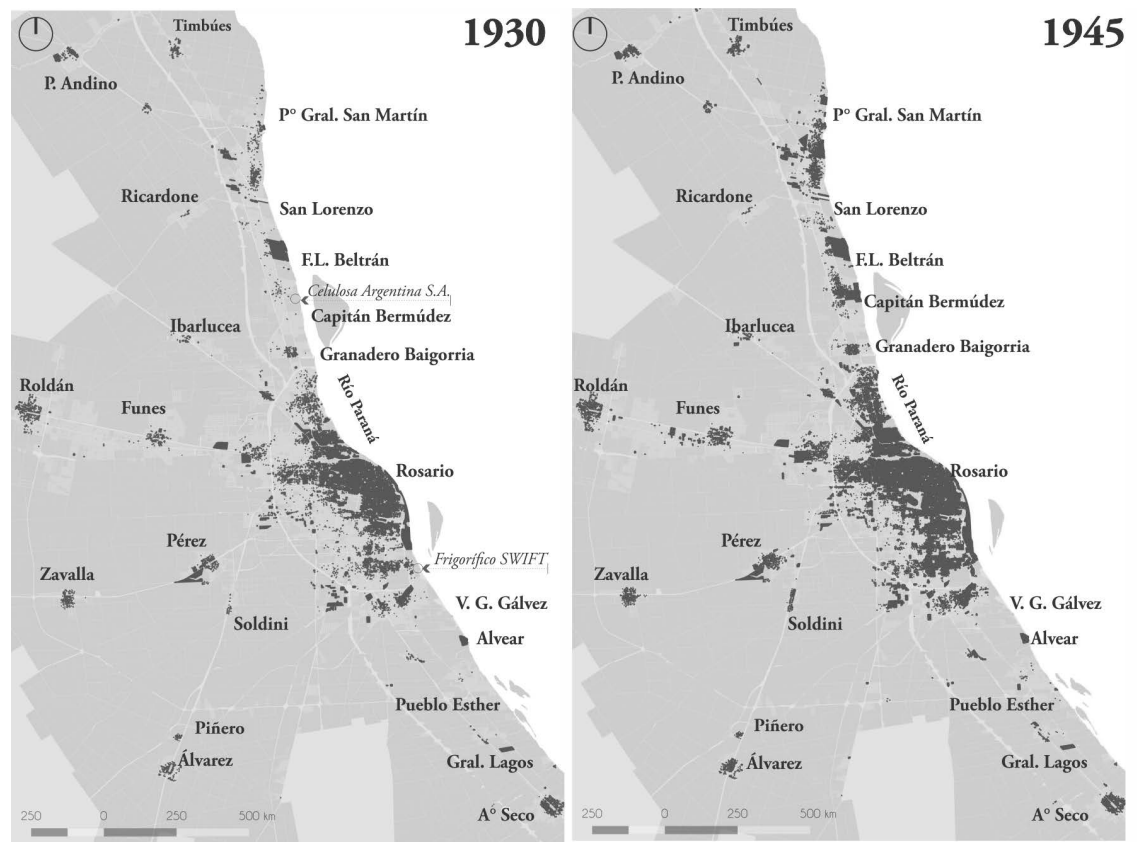

FIGURA 2 | Incremento de urbanización en el AMR entre 1930 y 1945

FUENTE: ELABORACIÓN PROPIA A PARTIR DE DATOS SCIT-SANTA FE

La figura 2 registra el crecimiento urbano en el AMR, siendo notoria tanto la expansión urbana del municipio de Rosario, como el incremento de la urbanización sobre el corredor norte a la vera del río. Justamente, este aumento de suelo urbano se asocia principalmente al proceso de instalación de industrias y al asentamiento de trabajadores cercano a las mismas. 
La industria sustitutiva de importaciones (ISI) se consolidó en la Argentina en la segunda posguerra, tendencia que es reflejada por el AMr. En los primeros ańos de la década de 1950, continuando la pauta del periodo anterior, se instalaron grandes y medianas industrias, como Verbano en 1950 en Capitán Bermúdez y Cerámica San Lorenzo en la localidad homónima. En el corredor sur se instaló Acindar en Villa Constitución, en 1951. Asimismo, a principios de la década de 1960, las nuevas inversiones de capital extranjero resultan protagonistas en el crecimiento productivo.

Las localidades ribereñas cercanas a Rosario constituyeron el ámbito ideal escogido, en particular por el capital extranjero, para localizar grandes plantas industriales especialmente vinculadas a la química y petroquímica, dada la proximidad de la destilería de petróleo y del oleoducto de Campo Durán-San Lorenzo, finalizado en 1959. En el periodo 1965-1968 se instalaron, así, Petroquímica Argentina S.A. (PasA), en Puerto General San Martín; Duperial, en San Lorenzo, y Sulfacid en Fray Luis Beltrán.

Esta proliferación industrial trajo consigo la expansión de las áreas urbanas por la instalación permanente de nuevos trabajadores y sus familias, que llevó a la conformación del corredor urbano-industrial que comprende desde la localidad de Puerto General San Martín hasta Villa Gobernador Gálvez y continúa de manera fragmentada hasta San Nicolás, provincia de Buenos Aires. Este proceso de conurbación, que se produjo a partir de la década de 1950, significó que muchas poblaciones se expandieran hasta encontrarse y conformar un solo continuo urbano (Galimberti, 2015). La conurbación ribereña así surgida se consolidó en las décadas siguientes, ya que, además de continuar el proceso de instalación productivo-industrial, también se desarrollaron las vías rápidas de comunicación: la autopista Rosario-Santa Fe, paralela a la Ruta Nacional 11 en el corredor norte; y la autopista Rosario-Buenos Aires, paralela a la Ruta Provincial 21 en el corredor sur. Estas sendas comunicacionales contribuyeron al incremento de la urbanización extendida en el territorio metropolitano.

Comenzando en la década de 1970, en muchas localidades del área se aprobaron numerosos loteos, los cuales, por su lejanía del tejido urbano existente, no respondían a las lógicas y necesidades internas de cada poblado, lo que originó diversos problemas vinculados a la infraestructura, servicios, movilidad y transporte, entre otros. En forma paralela, también a partir de dicho periodo, con la demanda de los mercados internacionales y los precios competitivos comenzó una producción masiva de oleaginosas que, junto a la industrialización de la soja, llevó tanto a la instalación de nuevas plantas de procesamiento como a la expansión de las existentes, muchas de las cuales comenzaron a desplegar instalaciones propias de embarque (Basadonna, 2002). Fue así que, a partir de la década de 1980, el frente fluvial del AMr incrementó notablemente las instalaciones portuarias, las cuales resultaron nodos estratégicos multimodales para la concentración y operación de cargas. Estos nuevos procesos acarrearon cambios en las dinámicas poblacionales y del uso de suelo.

Junto a tales procesos, la proyección de la autopista Rosario-Córdoba durante la década de 1970, aunque construida mayormente durante la década de 1990, anticipó la gran expansión urbana en parte del cuadrante oeste metropolitano. 
Especialmente las localidades próximas de Rosario, Funes y Roldán, comenzaron en este periodo a transformarse, como consecuencia de su atracción como casas finisemanales o de veraneo (figura 3). Tal tendencia se incrementó notablemente por el aumento acelerado de la superficie urbana para residencia permanente en el periodo que comienza en la última década del siglo xx, hasta la actualidad.

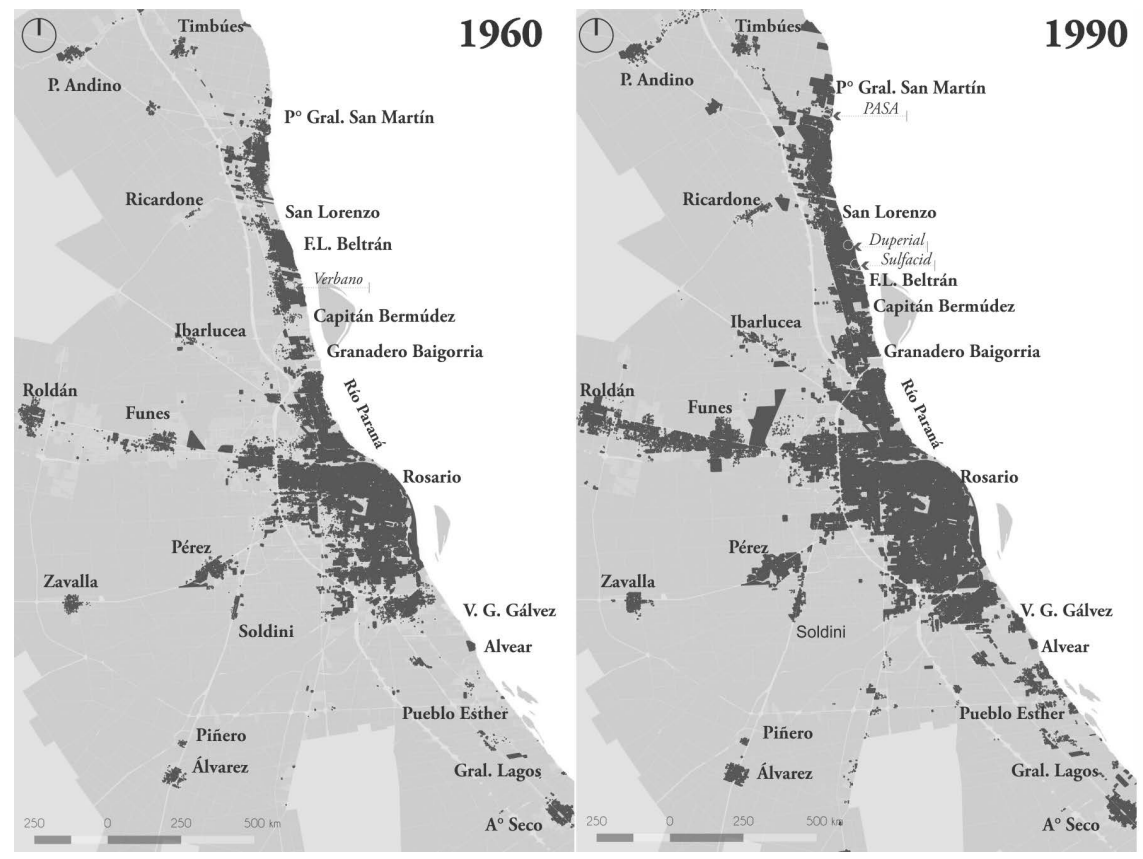

FIGURA 3 | Incremento de urbanización en el AMR entre 1960 y 1990

FUENTE: ELABORACIÓN PROPIA A PARTIR DE DATOS SCIT-SANTA FE

\section{Configuración actual de las dinámicas metropolitanas en el AMR}

Los avatares sociopolíticos y económicos que tuvieron lugar tanto a nivel internacional como nacional a partir de la década de 1980 ocasionaron numerosas transformaciones para la región. El AMR se posicionó como polo de exportación de gran relevancia internacional, resultando un nodo estratégico comunicacional y enclave logístico de gran importancia para Sudamérica. Los cambios ocurridos en las últimas décadas en el Gran Rosario son diversos, y abarcan distintos frentes temáticos: producción, sociedad, territorio y economía.

El ámbito geográfico de la región del Gran Rosario se transformó vertiginosamente, cambiando en gran medida los usos del suelo, de territorio rústico o rural a urbano. Se registra, a su vez, un notable incremento de la movilidad de la población, en especial hacia el periurbano de las localidades del área, aumentando considerablemente la dimensión de las plantas urbanas históricas de diversas comunas y municipios (figura 4). 


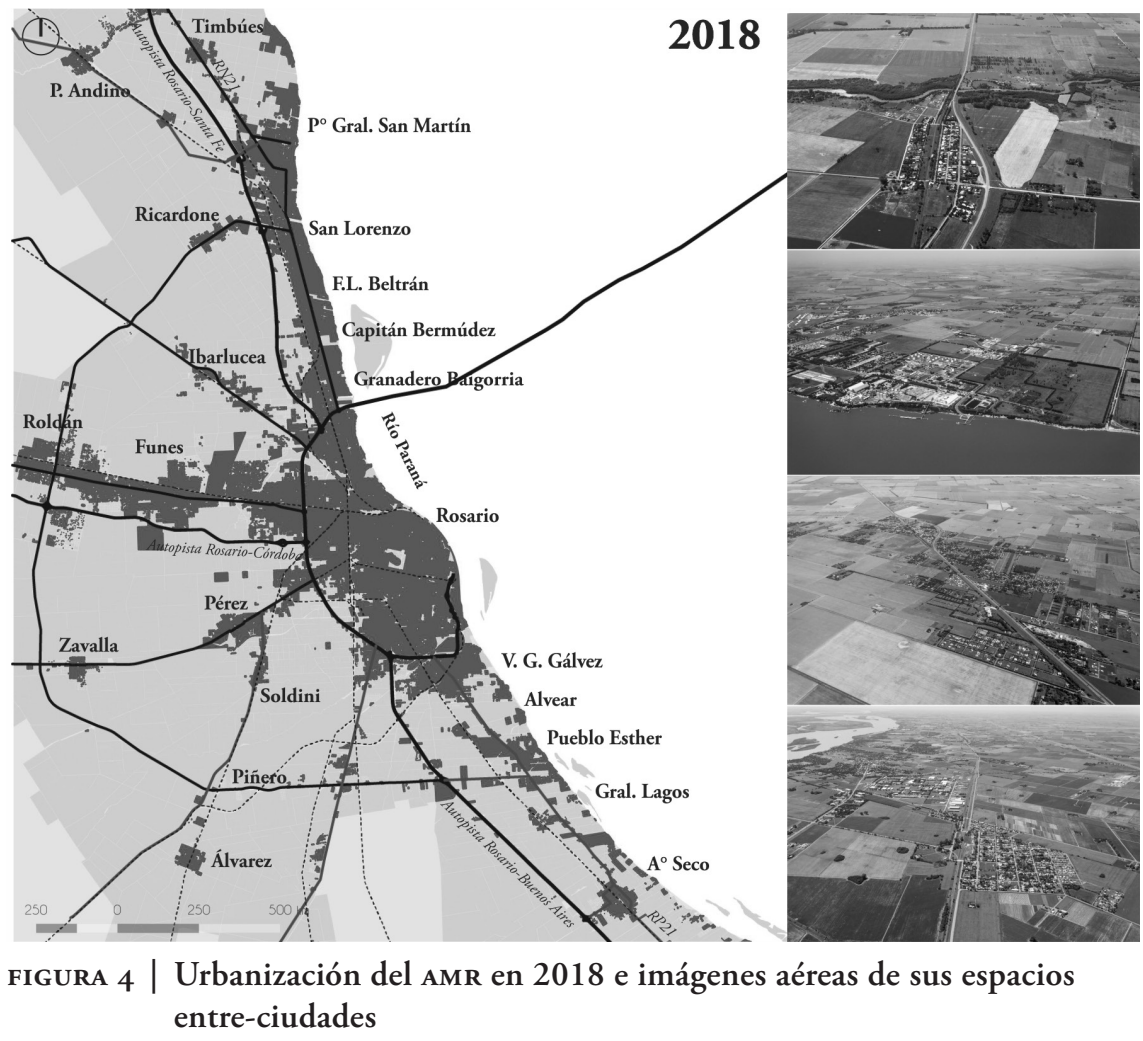

FUENTE: ELABORACIÓN PROPIA A PARTIR DE DATOS SCIT-SANTA FE Y FOTOGRAFÍAS ARCHIVO ECOM-ROSARIO

Ya desde fines de la década de 1960 y durante la década de 1970, en distintas localidades del AMr se aprobaron nuevos loteos vinculados tanto a componentes viales -rutas y autopistas- como a cursos de agua -ríos Paraná y Carcarañá y arroyos-, aunque generalmente localizados lejos de los núcleos urbanos. Sin embargo, no llegaron a ser ocupados ni a estabilizarse plenamente durante dicho periodo, situación que cambió entre 1990 y 2015, ya que no solo tendieron a consolidarse los loteos previos, sino a generarse nuevas urbanizaciones, transformando en gran medida las dinámicas de la región.

Como reflejan los datos de la tabla 1, entre 1990 y 2010 la ciudad de Rosario desaceleró su crecimiento poblacional en comparación con los periodos anteriores, a diferencia de gran parte de las localidades del AMR, que aumentaron notablemente su población. El cuadrante oeste es el ámbito geográfico con mayor crecimiento intercensal entre 1990 y 2010, con un incremento poblacional del 75,68\%, mientras en los corredores norte y sur ello se dio en un $31,23 \%$ y $33,53 \%$, respectivamente, y la ciudad de Rosario solo aumentó en 4,47\%. Durante dicho periodo, este sector territorial registra grandes cambios de uso del suelo; así, si bien se identifican nuevas actividades industriales, logísticas y del sector terciario, la mayor cantidad de superficie urbana generada corresponde a la residencial. Este notable aumento de pobladores tiene su correlato territorial, dado que se transformó una gran cantidad de suelo rural a urbano. 


\begin{tabular}{|c|c|c|c|c|c|c|}
\hline CIUDAD CABECERA & $\begin{array}{c}\text { HABITANTES } \\
\text { EN I99I } \\
\end{array}$ & $\begin{array}{c}\text { HABITANTES } \\
\text { EN 2OOI }\end{array}$ & $\begin{array}{c}\text { HABITANTES } \\
\text { EN 2OIO }\end{array}$ & $\begin{array}{l}\text { VARIACIÓN } \\
\text { I99I-200I }\end{array}$ & $\begin{array}{l}\text { VARIACIÓN } \\
\text { 200I-2OIO } \\
\end{array}$ & $\begin{array}{l}\text { VARIACIÓN } \\
\text { I99I-20IO }\end{array}$ \\
\hline Rosario & 907.718 & 908.163 & 948.163 & $0,05 \%$ & $4,40 \%$ & $4,46 \%$ \\
\hline \multicolumn{7}{|c|}{ LOCALIDADES DEL CORREDOR SUR } \\
\hline Alvear & 1.797 & 1.898 & 4.451 & $5,62 \%$ & $134,51 \%$ & $147,69 \%$ \\
\hline Arroyo Seco & 16.755 & 19.047 & 21.710 & $13,68 \%$ & $13,98 \%$ & $29,57 \%$ \\
\hline $\begin{array}{l}\text { Empalme Villa } \\
\text { Constitución }\end{array}$ & 5.480 & 6.267 & 6.410 & $14,36 \%$ & $2,28 \%$ & $16,97 \%$ \\
\hline Fighiera & 3.685 & 3.952 & 5.028 & $7,25 \%$ & $27,23 \%$ & $36,45 \%$ \\
\hline General Lagos & 1.729 & 2.616 & 4.112 & $51,30 \%$ & $57,19 \%$ & $137,83 \%$ \\
\hline Pavón & 757 & 827 & 1.880 & $9,25 \%$ & $127,33 \%$ & $148,35 \%$ \\
\hline Pueblo Esther & 2.305 & 4.557 & 7.195 & $97,70 \%$ & $57,89 \%$ & $212,15 \%$ \\
\hline Villa Constitución & 41.161 & 44.144 & 47.903 & $7,25 \%$ & $8,52 \%$ & $16,38 \%$ \\
\hline $\begin{array}{l}\text { Villa Gobernador } \\
\text { Gálvez }\end{array}$ & 63.078 & 74.658 & 80.769 & $18,36 \%$ & $8,19 \%$ & $28,05 \%$ \\
\hline \multicolumn{7}{|c|}{ LOCALIDADES DEL CORREDOR NORTE } \\
\hline Pueblo Andino & 1.403 & 1.543 & 2.226 & $9,98 \%$ & $44,26 \%$ & $58,66 \%$ \\
\hline Capitán Bermúdez & 25.944 & 26.914 & 29.425 & $3,74 \%$ & $9,33 \%$ & $13,42 \%$ \\
\hline Fray Luis Beltrán & 11.812 & 14.293 & 15.389 & $21,00 \%$ & $7,67 \%$ & $30,28 \%$ \\
\hline $\begin{array}{l}\text { Granadero Bai- } \\
\text { gorria }\end{array}$ & 21.915 & 32.249 & 37.333 & $47,15 \%$ & $15,76 \%$ & $70,35 \%$ \\
\hline $\begin{array}{l}\text { Puerto General } \\
\text { San Martín }\end{array}$ & 8.906 & 10.500 & 13.409 & $17,90 \%$ & $27,70 \%$ & $50,56 \%$ \\
\hline San Lorenzo & 40.535 & 43.039 & 46.239 & $6,18 \%$ & $7,44 \%$ & $14,07 \%$ \\
\hline Ricardone & 628 & 1.475 & 2.703 & $134,87 \%$ & $83,25 \%$ & $330,41 \%$ \\
\hline Timbúes & 1.959 & 2.702 & 4.294 & $37,93 \%$ & $58,92 \%$ & $119,19 \%$ \\
\hline \multicolumn{7}{|c|}{ LOCALIDADES DEL CUADRANTE OESTE } \\
\hline Acebal & 4.083 & 4.627 & 5.377 & $13,32 \%$ & $16,21 \%$ & $31,69 \%$ \\
\hline Álvarez & 4.171 & 4.928 & 6.175 & $18,15 \%$ & $25,30 \%$ & $48,05 \%$ \\
\hline $\begin{array}{l}\text { Coronel Domín- } \\
\text { guez }\end{array}$ & 601 & 736 & 1.091 & $22,46 \%$ & $48,23 \%$ & $81,53 \%$ \\
\hline Funes & 8.270 & 14.552 & 23.520 & $75,96 \%$ & $61,63 \%$ & $184,40 \%$ \\
\hline Ibarlucea & 582 & 1.303 & 4.402 & $123,88 \%$ & $237,84 \%$ & $656,36 \%$ \\
\hline Pérez & 20.131 & 23.578 & 27.578 & $17,12 \%$ & $16,96 \%$ & $36,99 \%$ \\
\hline Piñero & 440 & 517 & 1.816 & $17,50 \%$ & $251,26 \%$ & $312,73 \%$ \\
\hline Roldán & 9.013 & 11.252 & 14.299 & $24,84 \%$ & $27,08 \%$ & $58,65 \%$ \\
\hline Soldini & 1.583 & 1.990 & 3.312 & $25,71 \%$ & $66,43 \%$ & $109,22 \%$ \\
\hline Zavalla & 3.914 & 4.390 & 5.166 & $12,16 \%$ & $17,68 \%$ & $31,99 \%$ \\
\hline
\end{tabular}

TABLA I | Cantidad de población en 1991, 2001 y 2010 y variación intercensal en las localidades del Área Metropolitana de Rosario

FUENTE: ELABoraCión PROPIA A PARTIR DE DATOS DE CENSOS NACIONALES I 99i, 200 I Y 20 Io (INDEC) 
Los nuevos loteos generados por tal proceso fueron elegidos para vivir por muchas familias que se movilizaron desde sus localidades originarias o en las que trabajaban -mayormente de Rosario- a estas expansiones urbanas localizadas en comunas o ciudades cercanas a la ciudad cabecera. Tal transformación forma parte del proceso de suburbanización residencial que ha tenido lugar en todo el mundo a partir de las últimas décadas del siglo xx, y que en Argentina se ha profundizado a partir de 1990. Concomitante a este proceso es un imaginario que vincula la gran ciudad con inseguridad, violencia, contaminación, entre otros males, y que lleva a perseguir un modo de vida asociado al campo (no es casual que dichas urbanizaciones se autodenominen country), a la vivienda unifamiliar y en barrios cerrados que, además de brindar seguridad, otorgan diversos amenities (por ejemplo: canchas de tenis, campo de golf, amarras o caletas náuticas, club houses) (Galimberti, 2017). Estos productos inmobiliarios cerrados manifiestan un notable cambio en la relación de la ciudad con sus habitantes, ocasionando la fragmentación del tejido urbano y la cristalización de sus fronteras a través de vallas y servicios de seguridad privados:

En una situación de ahondamiento de las desigualdades sociales y de diferenciación creciente de los destinos de las distintas células urbanas, la fragmentación física de la ciudad parece ser el modo de gestión contemporáneo de los riesgos, tanto reales como imaginados, de la urbanidad. (Prévôt-Schapira \& Cattaneo Pineda, 2008, p. 83)

Por otro lado, muchas de las urbanizaciones llamadas "barrios abiertos" o "loteos residenciales" se han desarrollado debido a la presión de promotores inmobiliarios movilizados frente a las cuantiosas plusvalías generadas por la conversión de suelo rural a urbano en localidades que no suelen tener instrumentos normativos de usos del suelo o planeamiento urbano. Es de gran importancia remarcar que, hasta el año 2018, la mayoría de las localidades pertenecientes al AMr no contaban con Planes Urbanos ni con otros instrumentos de ordenamiento urbano-territorial. De esta forma, cada nueva urbanización propuesta por parte de promotores privados era analizada ad hoc por cada municipio o comuna, sin una visión integral previa de cada jurisdicción local o regional.

A su vez, frente a la presión de los inversores y dada la carencia de instrumentos normativos de urbanización, en numerosos casos de creación de suelo urbano en toda el AMR se registra la aprobación de estos loteos sin la exigencia de provisión de servicios y equipamientos. El resultado es la generación de cuantiosas hectáreas habilitadas para nuevas residencias, muchas veces alejadas del casco histórico del poblado, sin infraestructuras ni servicios básicos, con el consiguiente menor valor de dichos suelos en comparación con la ciudad central, provista de equipamientos e infraestructuras adecuadas. En estas circunstancias, muchas familias, a fin de acceder a una vivienda propia, adquieren esos lotes bajo la figura legal de fideicomiso, a veces incluso antes de que las urbanizaciones cuenten con los permisos necesarios. Esto sucede también porque, además de registrar contextos débiles de planeamiento urbano, dichos lotes presentan carencias en materia de control sobre las transformaciones de hecho. Además, en torno a ellos se registra gran cantidad de publicidad engañosa, dado que es frecuente que se promocionen estos barrios como dotados de servicios -red cloacal, gas natural, agua potable-, los que nunca llega a efectivizarse. 


\section{Expansiones urbanas en la jurisdicción de la comuna de Ibarlucea}

A modo de ejemplo, focalizaremos el estudio en la jurisdicción de Ibarlucea, comuna correspondiente al cuadrante oeste del AMr. Esta localidad linda con la ciudad de Rosario en su extremo noroeste, directamente vinculada por la ruta nacional número 34. Según los Censos Nacionales de Población, Ibarlucea pasó de registrar 582 habitantes en 1991, a 4402 en 2010. Es decir, presenta un incremento poblacional del $656 \%$. La dinámica del aumento de habitantes tiene una íntima relación con la expansión del área urbana en la localidad. Como presenta la figura 5, se ha producido una notable transformación de suelo rural a urbano, mayormente para usos residenciales, a través de barrios tanto abiertos como cerrados.

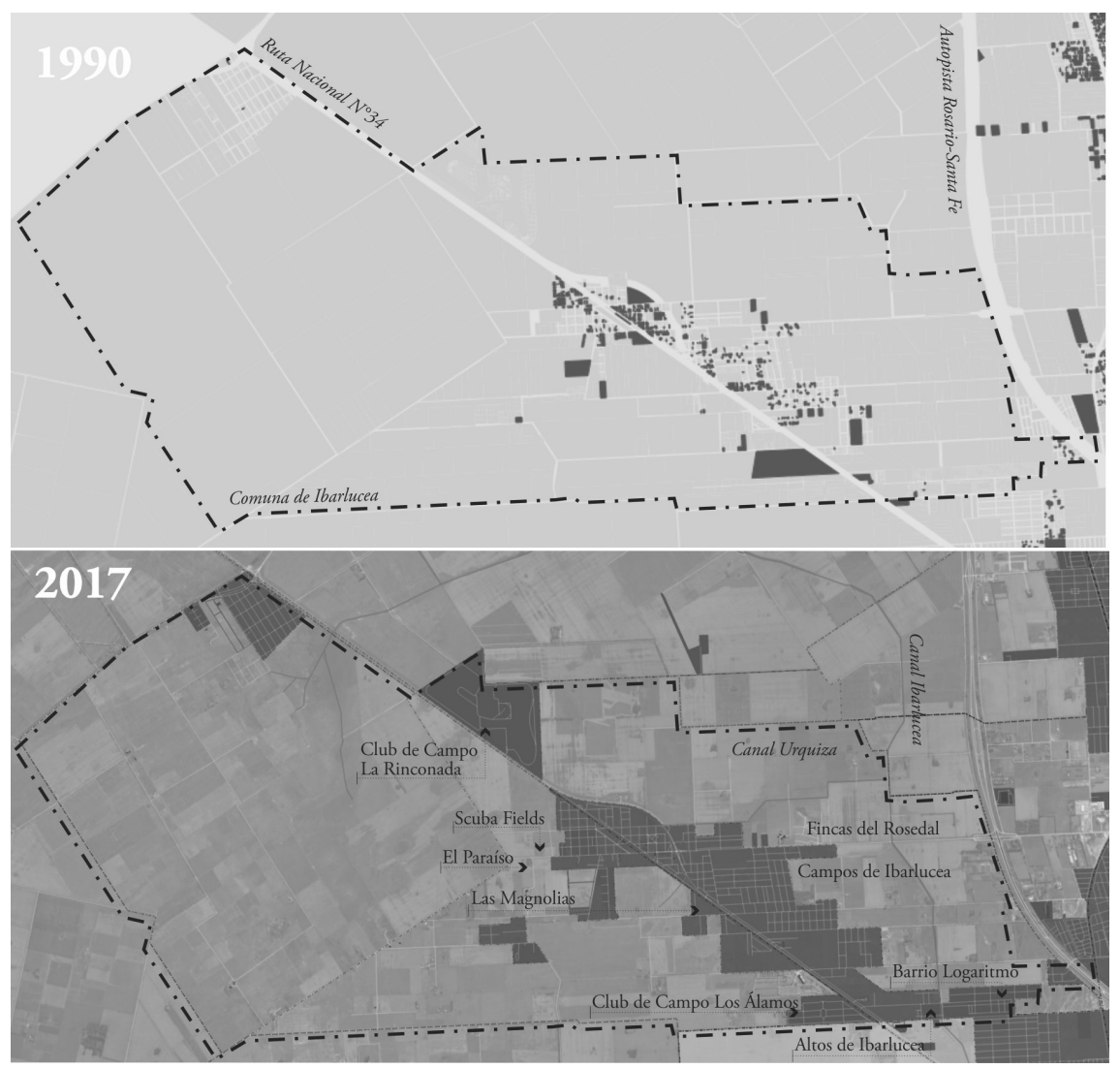

FIgURA 5 | Jurisdicción de la comuna de Ibarlucea.

Arriba: Áreas urbanizadas en 1990. Abajo: Áreas urbanizadas en 2017 FUENTE: ELABORACIÓN PROPIA A PARTIR DE DATOS SCIT-SANTA FE

Desde 1990 hasta la actualidad, se han aprobado aproximadamente 190 hectáreas correspondientes a urbanizaciones cerradas. Se destaca, en especial, el Club de Campo La Rinconada, de 120 hectáreas, con campo de golf, circuitos de equitación y cancha de polo, y que se localiza alejado del núcleo original. Asimismo, se han 
desarrollado los barrios cerrados Club de Campo Los Álamos, de 28 hectáreas; el barrio Logaritmo, en íntima asociación con el club homónimo; Campos de Ibarlucea y Scuba Fields (есом, 2018). Las nuevas urbanizaciones apelan a un exhaustivo marketing y estrategias publicitarias, según las cuales estos espacios garantizan una mayor calidad de vida, son más seguros, más vinculados a la naturaleza y a los deportes, en comparación con la vida en las ciudades tradicionales (figura 6).
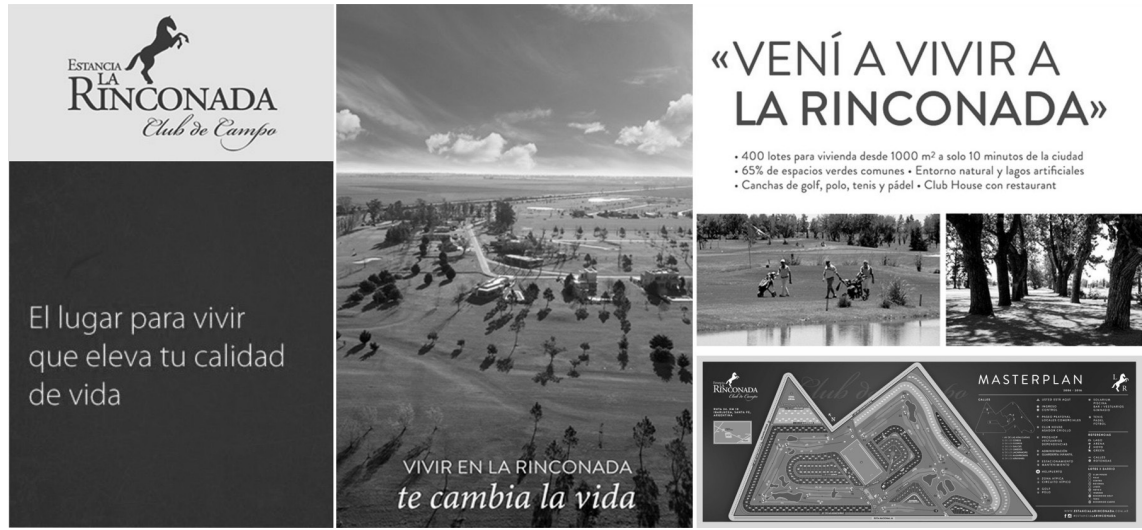

FIGURA 6 | Marketing y estrategias publicitarias del barrio cerrado "La Rinconada, Club de Campo"

FUENTE: HTTP://WWW.ESTANCIALARINCONADA.COM.AR/

A su vez, son numerosas las aprobaciones de nuevos loteos urbanos -barrios abiertos- realizados de manera dispersa en la jurisdicción, entre los que destacan Las Magnolias, El Paraíso, Altos de Ibarlucea, Fincas del Rosedal. Sin embargo, estas nuevas urbanizaciones no son acompañadas de servicios e infraestructuras acordes al incremento de suelo urbano. Así, en el año 2018 la localidad de Ibarlucea aún no contaba con agua potable ni red cloacal, solo un $8 \%$ de la planta urbana poseía red de gas natural y un $20 \%$ de sus calles se encontraban pavimentadas. Esta situación se complejiza si se tiene en cuenta la dinámica hídrica de Ibarlucea. $\mathrm{Al}$ encontrarse en su territorio los canales Urquiza y Salvat, el núcleo urbano se encuentra rodeado de zonas anegables. Por otra parte, la autorización de nuevo suelo urbano no se ha visto acompañada de la creación de equipamientos en materia de salud, educación, cultura, espacios públicos, entre otros. De esta forma, si bien su población se incrementó en más del $600 \%$ en veinte años, al no haberse desarrollado infraestructura acorde a dicho crecimiento se dificulta la vida cotidiana de sus habitantes, que se ven obligados a movilizarse frecuentemente a Rosario y/o a Granadero Baigorria, ciudades vecinas, para acceder a distintos servicios.

$\mathrm{Al}$ indagar sobre las causas que posibilitan la creación de suelo urbano con estas características, resulta fundamental reflexionar sobre el rol del Estado local y sus políticas de planeamiento urbano-territorial, o la carencia de estas. Respecto a la normativa vigente en la comuna de Ibarlucea, se destaca que su primer Plan Urbano se presentó en el año 2018 y solo posee como normativas previas asociadas 
a la urbanización, la Ordenanza n. ${ }^{\circ} 491$ de 2008, de usos del suelo; la Ordenanza n. ${ }^{\circ} 805$ de 2015 , que incorpora un manual de procedimientos para la aprobación de nuevas urbanizaciones residenciales; y la Ordenanza n. ${ }^{\circ} 852$ de 2016, en la que se establece una zona de amortiguamiento que deben proveer los nuevos desarrolladores de áreas urbanas que avancen sobre suelo rural. Es decir, todas las normativas mencionadas son recientes, desarrolladas luego de la mayor parte de las transformaciones territoriales registradas.

En este sentido, es fundamental comprender los efectos e impactos, tanto sobre el ambiente como en la sociedad, de los procesos de expansión de suelo urbano. En el caso de Ibarlucea, como en la mayoría de las localidades del AMR, dicha expansión se produce de manera disgregada en la Jurisdicción. La dispersión de áreas urbanas ocasiona gran conflictividad en la conectividad y movilidad de la población, dificulta la adecuada provisión de servicios e infraestructuras, y genera tanto impactos en materia de sostenibilidad como la yuxtaposición de usos incompatibles entre sí. Respecto a este último punto, uno de los mayores conflictos recurrentes en todas las localidades del AMR obedece a la aplicación de agroquímicos en las plantaciones extensivas del suelo rural (mayormente soja). Frente a la acelerada ocupación de suelo urbano, disperso en el territorio y rodeado de áreas rurales, se intensifica la problemática de los agrotóxicos lindantes a las áreas residenciales.

Por otra parte, la extensiva creación de suelo urbano para barrios cerrados, generalmente alejados de las plantas históricas, profundiza las problemáticas de segregación social, generando ciudades dentro de ciudades. La otra cara de estos desarrollos inmobiliarios cercados es la existencia de asentamientos irregulares, viviendas con graves déficits de habitabilidad y vulnerabilidad socioambiental. De este modo, la expansión urbana se caracteriza por la mera yuxtaposición de fragmentos diversos, pero sin puntos de contacto y relaciones entre sí, ampliamente desconectados y cuyos bordes distan ampliamente de ser espacios públicos de encuentro colectivo. Estas morfologías urbano-territoriales están moldeadas por las lógicas del mercado y no por la escala humana.

El paisaje actual del espacio metropolitano se configura, así, a partir de decisiones individuales e imágenes de grandes componentes productivos industriales, junto a infraestructuras de servicios, cercos con cámaras de seguridad de barrios cerrados, residencias en nuevos loteos y viviendas en asentamientos irregulares. A su vez, dado que esta expansión urbana generalizada carece notablemente de espacios públicos y lugares de encuentro casual, como plantea Ducci (1998), "estamos creando una anticiudad en el sentido original de la ciudad como lugar de encuentro, de los intercambios espontáneos que, ligados o no al comercio, han sido tradicionalmente característicos de la vida urbana" (p. 90). Como vemos en las figuras 7 y 8 , las dinámicas de urbanización en el AMR conforman una superposición de múltiples imágenes, resultado de imaginarios y deseos autónomos desvinculados entre sí; islas urbanas con lógicas distintas, carentes tanto de una legibilidad integral como de una construcción simbólica de apropiación colectiva. 

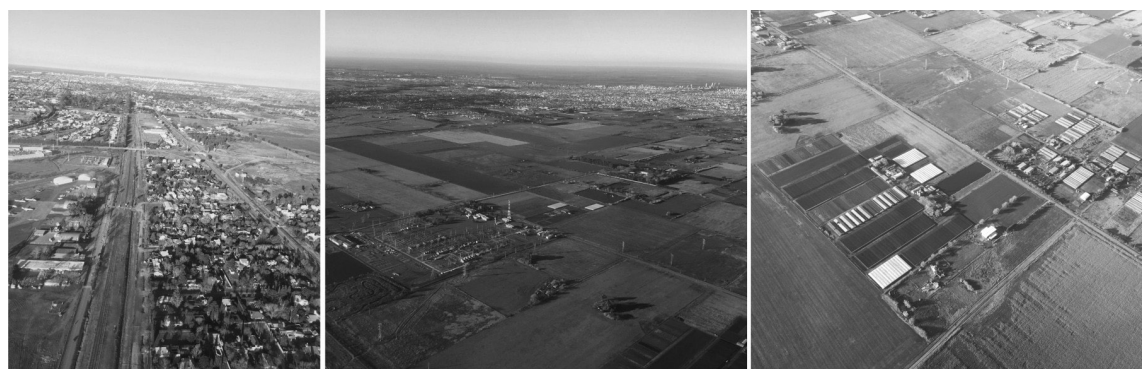

FIGURA 7 | Imágenes aéreas de las dinámicas espaciales del suelo suburbano del AMR

FUENTE: FOTOGRAFÍAS DE LA AUTORA

Los procesos de dispersión urbana en las ciudades de América Latina están íntimamente vinculados a las responsabilidades específicas y relaciones entre los diversos niveles gubernamentales. Especialmente en los ámbitos latinoamericanos, se reconoce una notable descoordinación de las actividades de los municipios independientes, los que muchas veces compiten entre sí para la atracción de inversiones. Por ello, siguiendo a Heinrichs et al. (2009), puede afirmarse que las políticas de dispersión urbana solo pueden ser exitosas si se fortalece la gobernanza multinivel a través de incentivos de cooperación voluntaria intercomunal, y de metas y objetivos comunes del desarrollo metropolitano. En esta línea resulta de particular importancia la creación del Ente de Coordinación Metropolitana (ЕСОм) de Rosario en el año 2010, como organismo conformado por la asociación voluntaria de municipios y comunas y legitimado por el Estado provincial a través de la sanción de la Ley 13.532 de Áreas Metropolitanas. Justamente, los municipios y comunas que pertenecen al есом definen y adhieren a las Directrices de Ordenamiento Territorial (рот) para el área. La primera directriz del всом-Rosario plantea la "definición de patrones de urbanización y uso del suelo sostenible", con el objetivo de definir políticas de urbanización basadas en:

la organización de los usos de suelo, a escala metropolitana, respondiendo a pautas de sostenibilidad ambiental y social, considerando las áreas con riesgo hídrico, las de protección rural, las áreas periurbanas y las franjas de restricción a la conurbación (...) se intenta, en otras palabras, reemplazar la usual modalidad de apropiación del suelo a través de simples loteos, por la idea de construcción integral de territorio y ciudad, con todos los atributos que este concepto conlleva. (Fein, 2014, p. 22)

Es en dicho contexto que la comuna de Ibarlucea, junto a otros veinticuatro municipios y comunas, inició en 2016 el desarrollo de sus planes urbanos locales. Si bien este proceso es de gran relevancia, dado que en el año 2018 trece localidades presentaron sus Planes Urbanos y otras doce se encuentran en curso, aún no podemos verificar los impactos que dichos planes tienen o tendrán en el ámbito metropolitano del AMr. 

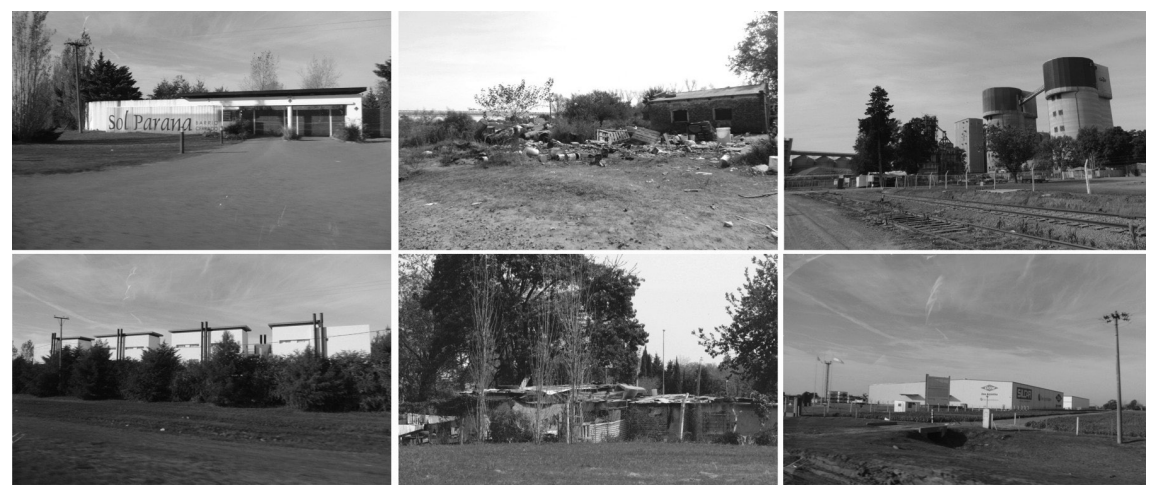

FIGURA 8 | Imágenes de circuitos peatonales en las dinámicas espaciales del suelo suburbano del AMR

FUENTE: FOTOGRAFÍAS DE LA AUTORA

\section{Aproximaciones finales}

La expansión urbana generalizada resulta una característica recurrente en las diversas áreas metropolitanas del mundo. Frente a la gran cantidad de hectáreas de paisajes intermedios, con lógicas y dinámicas diferentes tanto de la ciudad como del campo, claramente los instrumentos de análisis y proyecto tradicionales de las urbes compactas no son adecuados. Tampoco tiene sentido quedarse en la mera crítica negativa de la dispersión urbana. Siguiendo a Bruegemann (2006), los procesos de expansión urbana no solo son algo que ocurre y afecta en los bordes y las periferias de las áreas metropolitanas, sino que se los debe estudiar como partes de un sistema con componentes íntimamente vinculados, cuyas dinámicas impactan a toda la región. A su vez, estos sectores son elegidos por miles de pobladores, por lo cual también hay que indagar en los beneficios que otorgan, en las causas y motivos de su rápida transformación. Por esto, es fundamental abordar estudios particularizados e integrales de los procesos de expansión urbana, dado que tanto su análisis como su planeamiento requieren instrumentos específicos. También es fundamental estudiar particularmente cada caso de expansión urbana metropolitana, dado que cada uno presenta dinámicas propias con relación a su historia, los procesos de transformación y sus lógicas contemporáneas.

El análisis realizado sobre el AMR permite comprender que la generación de nuevo suelo urbano durante el siglo xx (1900-1980) está mayormente vinculada a la localización de nuevas industrias, fuentes de trabajo, y a la necesidad de residir cerca de las mismas, evitando movilidades, procesos a lo largo de los cuales se van consolidando nuevos sectores urbanos adyacentes a los ya existentes. La compacidad y continuidad son características de dicho periodo. Sin embargo, entre las décadas de 1960 y 1970 se iniciaron diversas operaciones inmobiliarias a través de las cuales se creó suelo urbano, y ello a partir de loteos generalmente localizados junto a rutas provinciales o nacionales, alejados de los núcleos urbanos históricos. No obstante, si bien estos casos fueron aprobados normativamente, muchos de los 
terrenos resultantes no fueron efectivamente ocupados, prosperando solo algunos emprendimientos para casas de fin de semana, como Funes y Roldán.

Ahora bien, frente a los nuevos procesos de metropolización que han acontecido a nivel global desde las últimas décadas del siglo xx, las dinámicas de expansión urbana en el AMR han ido cambiando, mayormente lideradas por intereses especulativos de desarrolladores, frente a un Estado local (municipal o comunal) generalmente carente de políticas, instrumentos y normativas de planeamiento urbanoterritorial. Junto a modelos suburbanos vinculados a un modo de vida verde, se profundiza el marketing de los loteos alejados de los núcleos urbanos, muchos de ellos bajo la modalidad de barrios cerrados, como espacios de tranquilidad para vivir. Diversos pobladores seleccionan estos espacios por sobre la ciudad tradicional, ya sea en búsqueda de más relación con la naturaleza, por una mayor seguridad o debido al menor precio del suelo, entre otras causas. Como se demuestra en las variaciones intercensales, son numerosas las familias que eligen habitar en nuevas urbanizaciones ubicadas en localidades cercanas a la ciudad cabecera del área.

En el marco señalado, se identifica una tríada clave de actores que generan el desarrollo de la expansión urbana generalizada: i) los desarrolladores inmobiliarios, que proponen y promueven la transformación de suelo rural en nuevos loteos y urbanizaciones; ii) el Estado, principalmente municipal o comunal, que suele carecer de instrumentos de planeamiento integral y que autoriza los desarrollos urbanos ad hoc, dependiendo del gobierno de turno; y iii) los habitantes que adquieren parcelas y lotes, incluso sin contar con autorizaciones formales, solo con promesas de infraestructuras y servicios -que rara vez los desarrolladores concretan según prometieran-, con la esperanza de acceder a la anhelada vivienda unifamiliar con jardín propio.

El paisaje intermedio del territorio metropolitano se configura, así, a través de numerosos contrastes que profundizan las desigualdades y la yuxtaposición inconexa de realidades diferentes. En este sentido, se agudiza la segregación residencial ${ }^{1}$ en estos espacios, dado que diversos grupos sociales se localizan en las áreas suburbanas pero en distintos enclaves que, si bien pueden estar muy próximos geográficamente, se encuentran socialmente alejados unos de otros. A su vez, la notable carencia de espacios públicos y equipamientos comunitarios en el desarrollo de la urbanización de la interfaz urbano-rural contribuye a imposibilitar el encuentro ciudadano, espacio de sociabilización y apropiación colectiva.

No es casual que estas dinámicas metropolitanas se produzcan especialmente en el territorio entre-ciudades, dado que es justamente dicho ámbito geográfico el que suele carecer de políticas, normativas e instrumentos de planeamiento y ordenamiento urbano. Ello ocurre en particular en comunas y municipios de pequeña escala y sin tradición técnica y política sobre estas cuestiones, por lo cual prevalece el libre albedrío de las decisiones individuales, que simplemente se yuxtaponen unas a otras, sin tener como sustento estudios analíticos previos o planificación integral.

1 Entendemos la segregación residencial como "la aglomeración en el espacio de familias de una misma condición social” (Sabatini, 2003). Dicho concepto implica "distanciamiento y separación de grupos de población de una comunidad” (Clichevsky, 2000, p. 8). 
En este sentido, resulta crucial el rol del Estado y la articulación de las decisiones políticas entre las distintas localidades que conforman el AMR. El planeamiento metropolitano coordinado y consensuado entre los diversos actores intervinientes resulta imprescindible frente a las dinámicas actuales de metropolización. A su vez, también es indispensable coordinar las estrategias y políticas habitacionales en los tres niveles del Estado -nacional, provincial y municipal o comunal-, dado que las políticas de acción sobre cada espacio geográfico tienden tanto a definirse como a aplicarse fragmentariamente, generando impactos no deseados e inclusive nuevas problemáticas que se superponen a las ya existentes.

\section{Agradecimientos}

La Dra. Cecilia Galimberti es Investigadora Adjunta del CURdiur (CONICET-UnR) de Argentina, el presente artículo ha sido elaborado en el marco de la Estadía de Investigación realizada en octubre de 2018 en el Grupo ARUCO de la Universidad de la Costa vinculada al Convenio Específico de Investigación entre ambas instituciones. Se agradece el financiamiento conjunto de dichas instituciones que ha posibilitado los resultados presentados en este artículo.

\section{Referencias bibliográficas}

Basadonna, J. A. (2002). Complejo Rosafé. El Río: desarrollo del interior. En J. M. Borthagaray (comp.), El Río de la Plata como territorio (pp. 247-282). Buenos Aires: Ediciones Infinito.

Bedini, M. A. \& Bronzini, F. (2016). The new territories of urban planning: The issue of the fringe areas and settlement filaments. Land Use Policy Volume, 57, 130-138. https:// doi.org/10.1016/j.landusepol.2016.05.020

Brenner, N. (2016). La explosión de lo urbano. Santiago de Chile: Ediciones ARQ.

Bruegmann, R. (2006). Sprawl: A compact history. Chicago and London: University of Chicago Press.

Ciccolella, P. (2014). Metrópolis latinoamericanas: Mas allá de la globalización. Buenos Aires: Editorial Café de las Ciudades.

Clichevsky, N. (2000). Informalidad y segregación urbana en América Latina. Una aproximación. Santiago de Chile: Comisión Económica para América Latina y el Caribe (Cepal). https://repositorio.cepal.org/bitstream/handle/11362/5712/1/S00100859_es.pdf

Colsaet, A., Laurans; Y., \& Levre, H. (2018). What drives land take and urban land expansion? A systematic review. Land Use Policy, 79, 339-349. https://doi.org/10.1016/j. landusepol.2018.08.017

De Mattos, C. (2015). Revolución urbana. Estado, mercado y capital en América Latina. Santiago de Chile: RIL editores / Instituto de Estudios Urbanos y Territoriales Uc.

Dieleman, F. \& Wegener, M. (2004). Compact city and urban sprawl. Built Environment, 30(4), 308-323. http://www.spiekermann-wegener.com/pub/pdf/Compact_city_BE.pdf 
Ducci, M. E. (1998). Santiago, ¿̨una mancha de aceite sin fin? ¿Qué pasa con la población cuando la ciudad crece indiscriminadamente? EURE, 24(72), 85-94. http://doi. org/10.4067/S0250-71611998007200005

eсом Rosario (2018). Ibarlucea 2030: Plan Urbano Local. Rosario: Ente de Coordinación Metropolitana de Rosario. https:/ecomrosario.gob.ar/web/uploads/ordenamiento/17/ PUL\%20IBARLUCEA.pdf?1550591558

Fein, M. (ed.). (2014). El Área Metropolitana de Rosario: directrices para la concertación de un modelo territorial. Cuaderno 3. Rosario: Есом Rosario.

Galimberti, C. (2015). La reinvención del rio. Procesos de transformación de la ribera de la Región Metropolitana de Rosario, Argentina. Rosario: A\&P Ediciones, Colección Tesis Doctorales - Universidad Nacional de Rosario, UnR Editora. https://rephip.unr.edu. ar/handle/2133/5475

Galimberti, C. (2017). Contrastes e inequidades en los territorios intermedios de la Región Metropolitana de Rosario, Argentina. Anales de Geografía de la Universidad Complutense, 37(1), 135-159. http://doi.org/10.5209/AGUC.55959

García-Palomares, J. C. (2009). Urban sprawl and travel to work: the case of the metropolitan area of Madrid. Journal of Transport Geography, 18(2), 197-213. https://doi. org/10.1016/j.jtrangeo.2009.05.012

Heinrichs, D., Nuissl, H., \& Rodríguez Seeger, C. (2009). Dispersión urbana y nuevos desafíos para la gobernanza (metropolitana) en América Latina: el caso de Santiago de Chile. EURE, 35(104), 29-46. http://doi.org/10.4067/S0250-71612009000100002

Hidalgo, R., Arenas, F., \& Santana, D. (2016). ¿Utópolis o distópolis? Producción inmobiliaria y metropolización en el litoral central de Chile (1992-2012). EURE, 42(126), 27-54. http://doi.org/10.4067/S0250-71612016000200002

Precedo Ledo, A. (2004). Nuevas realidades territoriales para el siglo XXI. Desarrollo local, identidad territorial y ciudad difusa. Madrid: Síntesis.

Prévot-Schapira, M. F. \& Cattaneo Pineda, R. (2008). Buenos Aires: la fragmentación en los intersticios de una sociedad polarizada. EURE, 34(103), 73-92. http://doi. org/10.4067/S0250-71612008000300004

Sabatini, F. (2003). La segregación social del espacio en las ciudades de América Latina. Washington, DC: Banco Interamericano de Desarrollo, Departamento de Desarrollo Sostenible. https://publications.iadb.org/es/publicacion/15146/la-segregacion-social-del-espacioen-las-ciudades-de-america-latina

Svampa, M. (2001). Los que ganaron: la vida en los countries y barrios privados. Buenos Aires: Biblos.

Van Noorloos, F. \& Steel, G. (2016). Lifestyle migration and socio-spatial segregation in the urban(izing) landscapes of Cuenca (Ecuador) and Guanacaste (Costa Rica). Habitat International, 54(1), 50-57. https://doi.org/10.1016/j.habitatint.2015.08.014 
